\title{
Acute Pancreatitis Related to COVID-19 Infection
}

\author{
Koichiro Yamamoto ${ }^{1}$, Kosuke Oka ${ }^{1}$, Hiroyuki Sakae ${ }^{1,2}$ and Fumio Otsuka ${ }^{1}$
}

Key words: acute pancreatitis, amylase, coronavirus disease 2019, lipase, SARS-CoV-2

(Intern Med 60: 2159-2160, 2021)

(DOI: 10.2169/internalmedicine.7400-21)

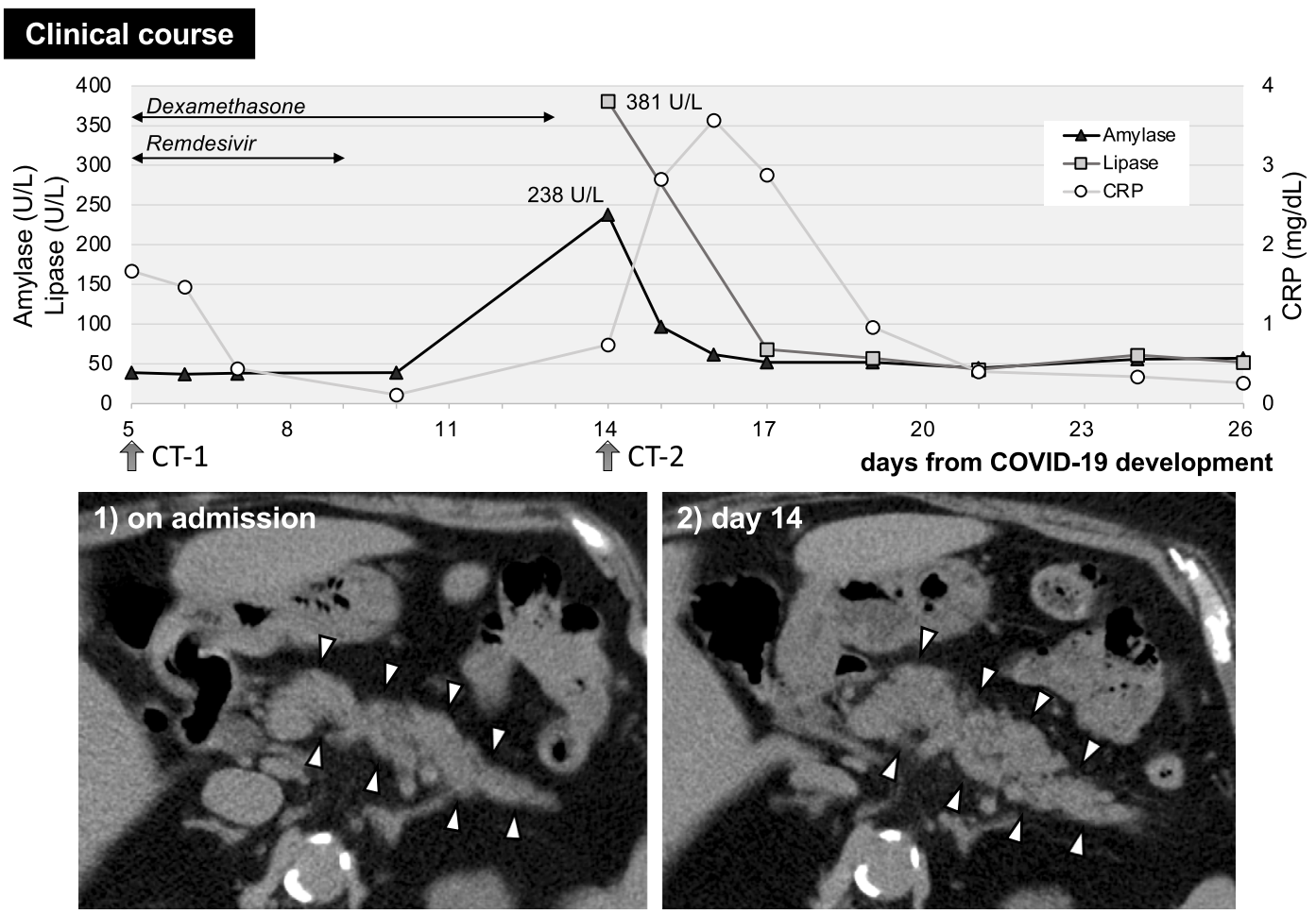

Picture.

A 70-year-old woman presented with coronavirus disease 2019 (COVID-19). Her symptoms included cough, which had persisted for 5 days and sore throat. She was obese (body mass index, $29.5 \mathrm{~kg} / \mathrm{m}^{2}$ ) and had diabetes mellitus, dyslipidemia, hypertension, and a history of cholecystectomy. Remdesivir and dexamethasone (6 mg) improved her symptoms. On the 14th day after the development of COVID-19, her serum levels of pancreatic enzymes were elevated (Picture, upper). Simultaneously, abdominal tenderness appeared and computed tomography showed an enlarged pancreatic parenchyma (Picture, lower). She was diagnosed with acute pancreatitis, which was ameliorated by fasting and fluid therapy.

COVID-19 is rarely complicated by acute pancreatitis (1). In such cases, angiotensin-converting enzyme 2 receptors in pancreatic cells may be associated with the pathogenesis (2). Considering that pancreatitis occurred after the administration of dexamethasone and remdesivir, these drugs might have been involved in the pancreatitis of our case. This case suggested that acute pancreatitis could develop immediately after treatment for COVID-19.

The authors state that they have no Conflict of Interest (COI).

${ }^{1}$ Department of General Medicine, Okayama University Graduate School of Medicine, Dentistry and Pharmaceutical Sciences, Japan and ${ }^{2}$ Department of Gastroenterology and Hepatology, Okayama University Graduate School of Medicine, Dentistry and Pharmaceutical Sciences, Japan Received: February 22, 2021; Accepted: March 30, 2021; Advance Publication by J-STAGE: May 14, 2021

Correspondence to Dr. Koichiro Yamamoto, pi291nd8@s.okayama-u.ac.jp 


\section{References}

1. Aloysius MM, Thatti A, Gupta A, Sharma N, Bansal P, Goyal H. COVID-19 presenting as acute pancreatitis. Pancreatology 20: 1026-1027, 2020.

2. Hadi A, Werge M, Kristiansen KT, et al. Coronavirus disease-19
(COVID-19) associated with severe acute pancreatitis: case report on three family members. Pancreatology 20: 665-667, 2020.

The Internal Medicine is an Open Access journal distributed under the Creative Commons Attribution-NonCommercial-NoDerivatives 4.0 International License. To view the details of this license, please visit (https://creativecommons.org/licenses/ by-nc-nd/4.0/).

(C) 2021 The Japanese Society of Internal Medicine Intern Med 60: 2159-2160, 2021 